reflecting the inadequacy of the service provided, and has the potential for influencing the political decision of the size of the allocation to health care. If resources do not match need the choice seems to lie between the "cost-benefit" list and the waiting list. I find the waiting list morally and practically the more acceptable; its power to gain more resources for the NHS has been well demonstrated.

But have we arrived at the stage where we should accept as inevitable the de facto rationing of the waiting list or the more explicit model of the Oregon experiment ${ }^{8}$ If we have not reached the limit of our ability to fund the increasing demands of the NHS the question we should be asking is not how are we going to ration care - that is, how are we going to rationalise denying some patients care, and in so doing destroy the fundamental principles of the NHS. Rather the question should be how can we ensure that an adequate proportion of the gross domestic product is devoted to the NHS to allow it to meet its responsibilities? Also, how can we ensure that what is already allocated to the NHS is used efficiently and effectively? This is exactly what the reforms are about. Now is surely not the time even to think about denying care to anyone. Anyone can solve the problems in this way; the challenge is how to maintain our commitment to the principles of a comprehensive health service when resources are not plentiful and demands are constantly rising.

\section{The way ahead}

Before the reforms the structure of the NHS did not ensure accountability and give confidence to those responsible for allocating the nation's resources that the service was being or ever could be run efficiently and effectively. The new structure has the potential for doing so and it is in everyone's interests that it succeeds. This requires that doctors and everyone else in the service do their best to make it work.

An important new requirement of the NHS Act 1990 is that the needs of each community shall be assessed and published annually in the Director of Public Health's report. Health authorities, as purchasers, are contracting provider units - for example, acute hospitals, community units-to provide specified quantities and quality of care, and this is monitored. It will soon become apparent what needs are not being met, and the public will be able to judge whether or not it is satisfied with the level ${ }^{1}$ and deployment of funding of their NHS. Once it is clear that more care cannot come from greater efficiency and effectiveness, the only argument against providing more money is that none is available. Who can assert this today when the United Kingdom spends less on health than most countries in the Organisation for Economic Cooperation and Development, our expenditure per capita being on a par with that of the poorer "olive" countries of Europe.

There is no need even to entertain the possibility of denying explicitly defined groups of NHS patients reasonable care in 1992 or the years immediately ahead. The time to consider the approach introduced by the North East Thames Regional Health Authority and by Oregon is when we truly cannot afford to pay for the quality and range of care that we want - but that time is not yet here. We have not reached that point in the NHS after 42 years of remarkable medical advances - personally, I doubt that we ever shall.

1 BMA. Leading for health: a BMA agenda for health. London: BMA, 1991 2 Thwaites B. The NHS: the end of the rainbow. Southampton: Institute of Health Policy Studies, 1987

3 Condition critical. Time 1991 Nov 25:34-42.

4 NHS Management Inquiry. Report. London: DHSS, 1983. (Griffiths report.)

5 BMA. CCSC guidance on clinical directorates. London: BMA, 1990.

6 Dixon J, Welch HG. Priority setting: lessons from Oregon. Lancet 1991;337: 891-4.

7 Klein R. On the Oregon trail: rationing health care. BMf 1991;302:1-2.

8 Smith R. Rationing: the search for sunlight. BMf 1991;303:1561-2.
British Medical Journal, London WC1H 9JR Fiona Godlee, MRCP, assistant editor

BMF 1992;304:299-304

\section{Health and the Environment}

\section{Environmental radiation: a cause for concern?}

\section{Fiona Godlee}

Radiation is an obvious focus for public concern. It is known to cause cancer and inspires anxiety becauseunlike that other widely available carcinogen, cigarette smoke-it is beyond the individual's control. But is there evidence that radiation at levels encountered in the environment is dangerous to health?

\section{Sources of radiation}

Ionising radiation has always been part of our natural environment, being emitted from the earth's core and the solar system (box). It is only in the past few centuries that man has added to natural background radiation: underground mining has led to exposure from radioactive rocks; air and space travel have taken people closer to the sources of cosmic radiation; modern building technology has contributed to the accumulation of the radioactive gas radon in homes; and the discovery of $x$ rays has spawned a whole industry of diagnostic and therapeutic radiology. ${ }^{1}$

The National Radiological Protection Board estimates that the average person in Britain receives a dose of radiation of $2.5 \mathrm{mSv}$ each year. Of this, $87 \%$ comes from natural sources-over half from radon decay products in the home. Medical radiation contributes $12 \%$. All other artificial sources-nuclear fall out, occupational exposure, and discharges from nuclear installations - account for about $1 \%$ of the total amount (fig 1).

The discovery of high levels of radon in homes in some areas of Britain has given the nuclear industry a chance to put its own contribution to environmental radiation into perspective and diverted public attention away from nuclear installations. But radon is a natural

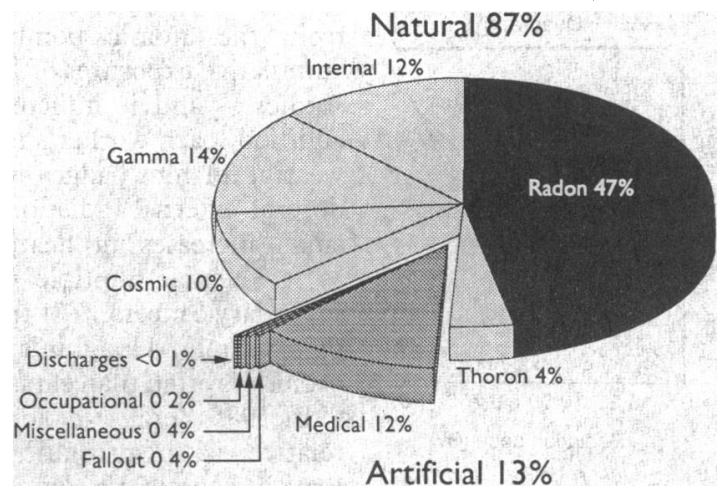

FIG 1-Contribution of different sources of radiation to annual average $\operatorname{dos}^{2}$ 
product of the environment; nuclear bombs and nuclear power are not. With the accident at Chernobyl and continuing anxiety about leukaemia clusters near. nuclear plants in Britain, the industry's public relations officers are still hard pressed to reassure us that environmental radiation is safe.

\section{Estimating the risks}

There is almost no direct evidence that low doses of radiation (below $100 \mathrm{mSv}$ ) are dangerous to health. ${ }^{3}$ But currently accepted mechanisms of causation of cancer are not consistent with the concept of a dose threshold, above which cancer will occur and below which there is no risk. It is therefore generally assumed that any risk from low dose radiation is so small that it is difficult to show epidemiologically.

Estimates of the risks from exposure to low doses of radiation are based on data from high dose exposure. These come from studies of survivors of the Japanese atomic bomb explosions, patients treated with radiotherapy, and workers in the nuclear industry.

Between 1950 and 1985 there were 340 excess deaths from cancer in a group of nearly 76000 Japanese survivors. ${ }^{+}$There have also been reports of short stature, reduced intelligence quotient (IQ), and increased rates of cancer later in life in their children. The dose of radiation to which these survivors were exposed has been calculated, and dose response curves for induction of cancer have been drawn up. By extrapolating the curve back towards zero the effects of radiation at low doses can be estimated.

But there are problems with this approach. Firstly, backward extrapolation along a dose response curve assumes that the relation between the dose and the response is linear. If the relation was instead quadratic or linear quadratic, as some models suggest (fig 2), ${ }^{6}$ the risks from radiation at low doses would be lower than predicted from the linear curve.

Secondly, the calculated doses received by the survivors are only estimates. They are based on such things as an individual's distance from the explosion and the shielding effect of intervening buildings. As a result of new evidence from Japan these estimates have recently been extensively revised, suggesting that the risks of cancer from radiation may be three to four times higher than was previously thought.

A third problem is the difference in the nature of the exposure. The doses inflicted by the bombing of Hiroshima and Nagasaki-in many cases over $200 \mathrm{mGy}$ - are 10 times the levels being considered in low dose chronic exposure and were inflicted over a short period. Risk estimates must also take into account the fact that extrapolating from the so called "high dose, high dose rate" exposure will further underestimate the risk of cancer from "low dose, low dose rate" environmental radiation."

A better basis for assessing risk from low dose chronic exposure may be studies on workers at nuclear installations. Occupational exposure is lower than that from the atomic bomb explosions - with average cumulative exposures of 1.4 and $7.8 \mathrm{mSv}$ in two recent studies ${ }^{7}$ - and is inflicted over a longer period. In addition, each worker's exposure is monitored by the wearing of film badges which record the cumulative dose of external radiation. These studies have found small increases in death rates from cancers such as leukaemia, multiple myeloma, lung cancer, and secondary cancers. ${ }^{-4}$ At the same time some cancersfor example, Hodgkin's disease and liver canceroccur less often than expected.

In 1985 Beral et al found a significant increase in relative risk of prostatic cancer in workers from the British Atomic Energy Authority; the increase was strongly related to radiation dose. ${ }^{10}$ In a second study in

\section{Some basic physics}

$x$ Rays, $\gamma$ rays, and $\alpha$ and $\beta$ particles are emitted from unstable nuclei during radioactive decay. They are all forms of ionising radiation, so called because they possess sufficient energy to ionise atoms by removing electrons from them. Other forms of radiation-heat, light, radio waves, and microwaves-lack sufficient energy to do this and are therefore called non-ionising. ( Particles, comprising two protons and two neutrons, are positively charged, heavy, and slow moving. They are emitted by uranium, thorium, and plutonium, and they ionise by dragging away electrons. $\beta$ Particles, which are positive or negative electrons, are small and fast and less ionising than $\alpha$ particles. $x$ Rays and $\gamma$ rays are types of electromagnetic radiation. They are not charged but penetrate further than $\alpha$ and $\beta$ particles. The biological effects of different types of radiation depend on the energy delivered per distance travelled, or the linear energy transfer (LET). $\alpha$ Particles (high linear energy transfer) have greater biological effects than $\beta$ particles and $\gamma$ rays (low linear energy transfer).

\section{Measuring radioactivity}

Bequerel $(\mathrm{Bq})$ - a measure of the ionising activity of a sample; $1 \mathrm{~Bq}$ is one nuclear transformation per second.

Gray (Gy) - a measure of the amount of ionising energy absorbed by the body, or the absorbed dose; $1 \mathrm{~Gy}$ equals one joule of energy absorbed per kilogram of tissue. The gray has replaced the old rad: 1 Gy equals $100 \mathrm{rad}$.

Sieverts $(\mathrm{Sv})$ - take into account the different linear energy transfer of different types of radiation. Multiplying the absorbed dose by one for $\beta$ particles and 20 for $\alpha$ particles gives the dose equivalent in sieverts. The sievert has replaced the old rem: $1 \mathrm{~Sv}$ equals $100 \mathrm{rem}$.

1988 , this time on workers in the Atomic Weapons Establishment, the increased risk of prostatic cancer was less evident, except in those workers who were also exposed to internal radiation from ingesting radionuclides such as polonium, uranium, and tritium. Beral et al concluded that the increase in prostatic cancer was unlikely to be due to external radiation alone. Other studies - for example, one of survivors of atomic bomb explosions ${ }^{11}$ and a recent one of over 95000 British radiation workers ${ }^{9}$ - have failed to find any effect on mortality from cancer of the prostate.

The risk estimates for low dose radiation remain highly uncertain and are constantly being revised. The 1990 estimate from the International Commission on Radiological Protection-0.05 cancer deaths per Sv for a population of all ages - is based on a linear, no threshold model and incorporates a "dose rate effectiveness factor" to correct for chronic exposure." It is four times higher than the last estimate in $1977 . .^{12}$

\section{Leukaemia clusters}

In 1983 a Yorkshire Television programme, Windscale: the Nuclear Laundry, alleged that emissions from the nuclear reprocessing plant in west Cumbria had caused a local increase in the incidence of leukaemia in children. Reports subsequently confirmed the cluster around Windscale (renamed Sellafield in an attempt to shed unhappy associations) and showed other clusters near nuclear installations at Dounreay in Scotland and at Aldermaston and Burghfield in Berkshire. ${ }^{1+16}$ Sellafield - the only reprocessing plant out of the four installations-discharges much the highest level of radiation into the environment and is associated with the largest excess risk of childhood leukaemia: a 10 fold increase in the number of cases over 30 years compared with a twofold increase near the other three installations. linear, quadratic, and linearquadratic models 


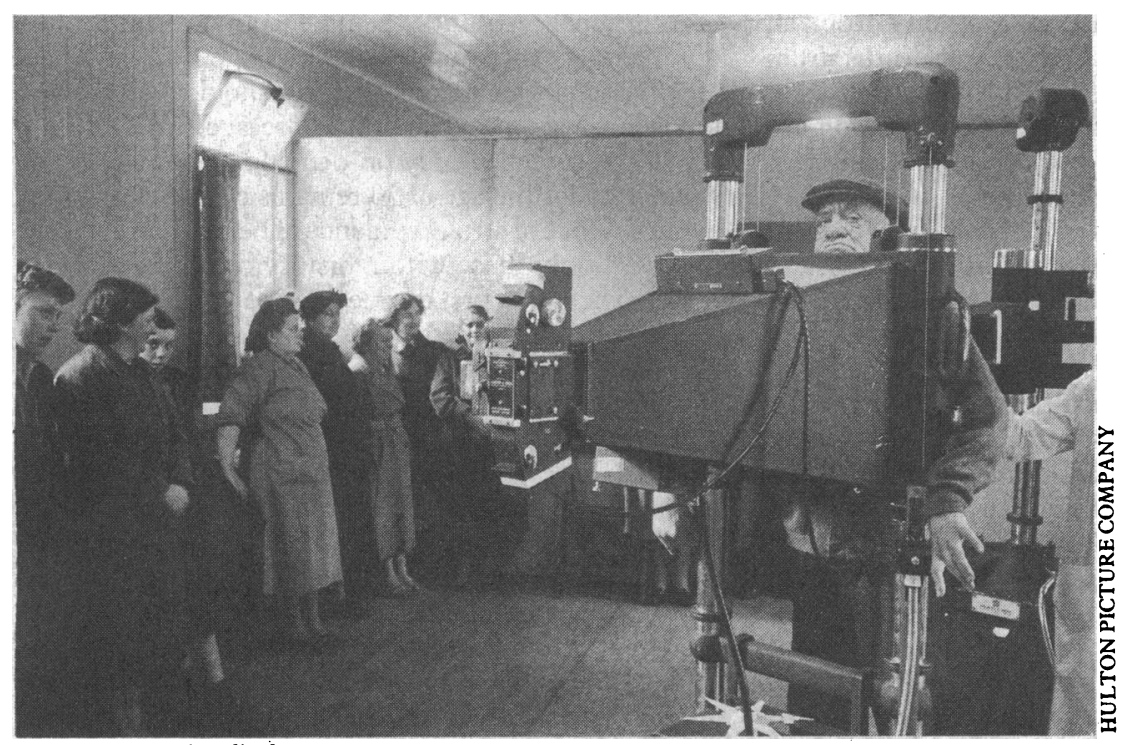

The early days of medical radiation saw much misguided enthusiasm

Analysis of data from nuclear installations throughout England and Wales showed similar trends. ${ }^{17}$ Between 1969 and 1978 mortality from all leukaemias in those aged $0-24$ years was $15 \%$ higher in districts near nuclear installations than in matched control districts, and mortality from lymphoid leukaemia was $21 \%$ higher. ${ }^{18}$ Although small by comparison with the 10 -fold excess around Sellafield, these figures reached significance because of the large numbers being studied. The Committee on Medical Aspects of Radiation in the Environment, an independant advisory body, concluded that the clusters, especially the one around Sellafield, are unlikely to be due to chance. ${ }^{16}$ The reason for the clustering, however, remains a mystery.

The committee found little evidence to incriminate environmental radiation. The doses that the children are thought to have received are, says the committee, far too low to explain the increase in incidence. Samples of bone marrow from 1 year old children in Britain have shown an average dose from background radiation of about $990 \mu \mathrm{Sv}$. The additional dose to the bone marrow of 1 year olds living near Sellafield is only $170 \mu \mathrm{Sv}$ and near Dounreay only $4.5 \mu S v .{ }^{19}$ These data have been the mainstay of arguments from the nuclear industry against any association between discharges from nuclear plants and leukaemia clusters.

Further evidence against environmental radiation as the major cause of the clusters comes from a study that found a similar excess risk of leukaemia in areas where nuclear installations were planned but either never built or built after the data on mortality had been gathered.$^{20}$ This implies that radiation is not responsible and that potential and existing nuclear sites share some as yet unrecognised risk factor for leukaemia. Other explanations for the clusters need to be examined.

One alternative explanation, though not widely accepted, is that childhood leukaemia is a rare consequence of some as yet unidentified infection..$^{21-23}$ The main proponent of this theory, Dr Leo Kinlen, director of the Cancer Epidemiology Unit in Oxford, cites the fact that infectious causes, in the form of specific viruses, are well established for several animal leukaemias and for adult $\mathrm{T}$ cell leukaemia. In addition, he believes that the pattern of leukaemia in the areas studied fits the model of an epidemic; starting in the 1950 s, reaching a peak in the late 1970 s, and then dying away again. Kinlen suggests that building nuclear installations in isolated areas provides the ideal set up for an infectious epidemic. People who have previoùsly remained unexposed to an infectious agent are susceptible to infection. Mixing with a population of exposed individuals will ensure a large dose of the agent and increase the chances of infection. The infectious theory is likely to remain speculative unless a specific agent is identified.

Meanwhile, a new hypothesis-that a man's exposure to radiation is associated with an increased risk of leukaemia in his children-has shifted the spotlight back on to the nuclear industry. The hypothesis was formulated during analysis of the Sellafield data. ${ }^{24}$ The risk of leukaemia was found to be raised if a child's father had been employed at Sellafield and was highest when the father's cumulative exposure exceeded $100 \mathrm{mSv}$ or when he was exposed to more than $10 \mathrm{mSv}$ in the six months before the child's conception. The study found no link with direct environmental exposure to the child from, for example, using local beaches or eating seafood or home grown vegetables.

One much quoted animal study lends limited support to the idea that childhood cancers might be caused by previous parental exposure. Irradiation of male mice has been shown to increase the risk of leukaemia (and lung cancer) in their offspring. ${ }^{25}$ The study by Gardner et $a l^{24}$ has proved more difficult for the nuclear industry to poke holes in than previous work. This is not only because of its statistical rigour but also because, by moving away from the idea of a direct effect of radiation, it may explain the discrepancy between Sellafield's small contribution to local children's overall dose of environmental radiation and the 10 -fold increase in the risk of childhood leukaemia. Gardner's findings are, however, based on a small number of cases on which a large number of tests were performed and must therefore be considered as preliminary.

Other studies have found no effect from previous parental exposure. Children of survivors of the atomic bomb explosions at Hiroshima and Nagasaki have not shown an increased risk of cancer. ${ }^{26} 27$ And a casecontrol study of children with leukaemia and lymphoma in the area around Dounreay found no association with the fathers' exposure to radiation..$^{28}$ The Japanese data, however, deal with acute massive exposure to radiation and may not be relevant to chronic low dose exposure; and although the Dounreay study failed to confirm Gardner's hypothesis, the small number of cases meant that it did not have the power to refute it. More work and larger studies are needed to test the hypothesis.

\section{Medical radiation}

Medicine is the largest source of manmade radiation. It also offers the greatest scope for reducing the dose of radiation delivered to the population. ${ }^{29}$ The doses now used are, however, small relative to background radiation, and any excess risk is difficult to detect.

The early days of medical radiation were characterised by much misguided enthusiasm. Ringworm, acne, birthmarks, bursitis, and sinusitis were among the benign conditions treated with deep radiation therapy. The scalps of more than 10000 children in Israel, and a similar number in New York, were irradiated for ringworm between 1949 and 1960 with the intention of making the hair fall out so that the skin could be more effectively treated. ${ }^{30}$ It was only in the 1960 s that an awareness of the potential dangers began to dawn. Studies in America comparing irradiated and nonirradiated children infested with ringworm have shown a sixfold increase in cancers of the thyroid as well as smaller increases in brain cancers and leukaemia. ${ }^{31} 32$

High doses of radiation were also delivered to induce menopause in patients with menorrhagia and in mass screening for tuberculosis. In Britain the radiological vogue was for treating ankylosing spondylitis. A study of 14111 patients with the disease who were given a single course of $x$ ray treatment between 1935 and 1954 


\begin{tabular}{lc}
\hline & $\begin{array}{c}\text { Average lifetime } \\
\text { risk of fatal } \\
\text { cancer } \\
\text { (per million) }\end{array}$ \\
examination & $2-7$ \\
Skull & $0 \cdot 7-2$ \\
Chest & $15-40$ \\
Thoracic spine & $30-100$ \\
Lumbar spine & $20-60$ \\
Abdomen & $15-55$ \\
Pelvis & \\
Intravenous & $60-200$ \\
$\quad$ urography & $50-170$ \\
Barium meal & $100-350$ \\
Barium enema & \\
\hline
\end{tabular}

showed a two thirds increase in mortality from all causes and a nearly fivefold excess of deaths from leukaemia. ${ }^{33}$ In the past twenty years, the doses used in. medicine have been greatly reduced and radiation has been increasingly reserved for treating malignant conditions and for diagnostic purposes.

Diagnostic radiology offers perhaps the only piece of direct evidence that low doses of radiation are a risk to health. This comes from some studies performed in the 1950s which showed that children born to women who were irradiated during pregnancy had an increased incidence of cancer. ${ }^{34}$ As a result of such findings, the 10 day rule - which states that women of reproductive age should have $x$ ray examinations only within 10 days of the start of their last menstrual period-has been adopted in Britain. It remains controversial, however, and is not used by the American College of Radiology. The International Committee on Radiological Protection now recommends that there is no need to limit exposure until after the fourth week of pregnancy. ${ }^{35}$

In Britain diagnostic medical $x$ rays comprise almost nine tenths of the total collective dose of radiation from all manmade sources..$^{29}$ The table shows the estimated risk of cancer from different types of radiography. About 25 million $x$ ray examinations are performed each year in the NHS, one third of them chest examinations. France and the United States perform about twice as many $x$ ray examinations as Britain per head of population, and Japan averages four $x$ ray examinations per person per year (National Radiological Protection Board, personal communication).

Many of these investigations are unnecessary. According to a recent report from the Joint Working Party of the National Radiological Protection Board and the Royal College of Radiologists, at least one fifth of all $x$ ray examinations performed in Britain are clinically unhelpful, ${ }^{36}$ and in one study a third of patients sent to an orthopaedic clinic in Scotland had to have repeat examinations because their original films were not provided by the general practitioner. ${ }^{37}$ The National Radiological Protection Board estimates that $3-15 \%$ of $x$ ray examinations are repeated because of unsatisfactory results at the first attempt. ${ }^{29}$ The radiation from unnecessary diagnostic irradiation amounts to 7500 man $\mathrm{Sv}$ and could be responsible for $100-250$ of Britain's 160000 yearly deaths from cancer.

\section{Reducing the dose}

The contribution to environmental radiation from radiography could be tackled by reducing both the number of investigations and the dose delivered with each one. The Royal College of Radiologists and the National Radiological Protection Board have recently issued new guidelines on the use of routine radiological investigations. ${ }^{36}$ Preoperative chest radiography is only indicated in patients about to undergo cardiac or pulmonary surgery or in whom there is a strong suspicion of malignancy or tuberculosis. Skull radiography should not be performed routinely after head injury, and employment related screening is discouraged. In 1983 an estimated 140000 "employment related" chest radiographs were taken in Britain, delivering an annual collective dose of about 5 man Sv. They should be taken only when clinically justifiedfor example, in workers from countries where tuberculosis is endemic.

These can only ever be guidelines. The Royal College of Radiologists recognises that imposing absolute limits on the amount of radiation to which a patient can be exposed would be impossible. Acute medical emergencies will always take precedence over the long term risks to the patient from additional exposure to $x$ rays. But the college is creating an atmosphere in which clinicians must justify their requests for radiological investigations.
Additional restraint is being encouraged in the area of screening for treatable diseases. The Forrest report recommends that mammography should be reserved for women aged 50 to $64 .{ }^{38}$ Those aged 65 and over should be screened only on demand. The position of women under the age of 50 remains controversial, but in the absence of strong evidence of benefit the advice is to screen only those with a history of premenopausal breast cancer in a first degree relative.

As well as reducing the number of radiological investigations there is scope for reducing the dose administered with each one. Simply by making optimum use of existing technology the average radiation dose to patients could be halved. ${ }^{36}$

Proper use of gonad shields would reduce the risk of severe hereditary disease. A survey in 1980 found that gonad shields were not being used as often as they should be, especially in children..$^{39}$ They should be used in all patients of or below reproductive age.

Computed tomography delivers relatively high doses of radiation, and doses have increased rather than decreased as technology has advanced. This is because the speed of imaging has increased dramatically, leading to a rise in the number of slices imaged on each patient. At the same time little progress has been made towards reducing the dose of radiation given with each slice. Computed tomography comprises only $2 \%$ of $x$ ray examinations in Britain but contributes $20 \%$ of the effective collective radiation dose ${ }^{36}$ Routine abdominal computed tomography delivers an effective dose of $9 \mathrm{mSv}$ - as much as a barium enema.

The future of diagnostic imaging may be radiation free thanks to the arrival of nuclear magnetic resonance. But this form of imaging also has its limitations. At the moment it is expensive and there are practical problems in encasing patients inside the magnet. There have also recently been some anxieties about its safety in certain patients. ${ }^{40}$

\section{Radon}

The biggest contribution to natural radiation comes from radon, a colourless, odourless gas given off by uranium. Granite contains uranium and emits radon into the atmosphere, especially in areas where the rock is heavily fractured. Radon emits $\alpha$ particles as it decays to radioactive polonium, lead, and bismuth. These "radon daughters," $\alpha$ emitters in their own right, are then inhaled.

In the past uranium miners were heavily exposed to radon, and studies have shown them to be at increased risk of lung cancer. ${ }^{4142}$ People living in areas well endowed with granite are also exposed, especially since modern building techniques have improved insulation in houses. In Pennsylvania an engineer at a nuclear power station set off radiation alarms as he arrived at work. His house, well insulated and built on ground rich in granite, was found to have an indoor radon level of $100000 \mathrm{~Bq} / \mathrm{m}^{3}$. Higher levels have since been recorded in both America and Britain.

The United States Environmental Protection Agency has set $150 \mathrm{~Bq} / \mathrm{m}^{3}$ as the concentration of radon at which remedial action should be taken. It estimates the lifetime risk of fatal lung cancer from exposure at this level to be $2 \cdot 4 \%-9 \%$. On this basis 5000 to 20000 of the 130000 annual deaths from lung cancer in the United States could be attributed to exposure to radon.

In Britain the action level for existing houses has recently been halved from 400 to $200 \mathrm{~Bq} / \mathrm{m}^{3}$ in response to the National Radiological Protection Board's reappraisal of the risk from radon in homes. ${ }^{43} \mathrm{An}$ estimated 100000 houses in the United Kingdom currently exceed this level, most of them in Devon and Cornwall. The average concentration of radon in homes across the country is estimated at $20 \mathrm{~Bq} / \mathrm{m}^{3}$. 


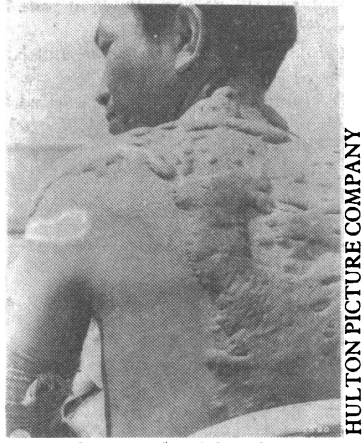

Most data on the risks of radiation come from survivors of fapanese atomic bomb explosions
This confers an average lifetime risk of lung cancer of $0.3 \%$ and implies that one in 20 lung cancers in Britain (about 2000 cases a year) may be due to radon exposure at home ${ }^{43}$ Radon in homes in Britain is measured by the National Radiological Protection Board on behalf of the Department of the Environment. Surveys are free if, because of the locality, the board considers it likely that the radon level will be raised or if the house is in an area where little is known about radon levels. Otherwise the householder is charged $£ 29.60$ plus value added tax.

Advice on remedial action from the Building Research Establishment aims at preventing radon from entering houses. ${ }^{44}$ The air pressure inside houses tends to be lower than outside because of the effect of wind and temperature. As a result, soil gas containing radon is drawn up into the house. This can be prevented by drawing air from beneath the floor with an extractor fan. According to the Building Research Establishment, the cost of such remedial action would be $£ 500-£ 1500$.

It is important, however, to stress that at the moment there is little direct evidence that radon at levels found in houses causes lung cancer. Current risk estimates are based on extrapolation from the known effects on uranium miners and, like those based on the atomic bomb survivors, they assume a linear, no threshold relation between the dose of radon and the incidence of lung cancer. Estimates are corrected for the differences between the miners-all adult men performing heavy physical tasks breathing at high rates in a dust laden atmosphere-and the population at large.

Another factor that must be corrected for is smoking. Most of the miners on whom risk estimates have been based were heavy smokers. Studies that take this into account have led to the conclusion that smoking increases the carcinogenic effects of radon. The lifetime risk of exposure to radon for smokers is estimated to be 10 times that for non-smokers.

This has led to controversy over whether nonsmokers are at any increased risk of lung cancer from low doses of radon. A study in Colorado of 516 non-smoking uranium miners found only a small excess of lung cancers. ${ }^{45}$ This, in concert with the other uncertainties, prompted the authors of a recent review to suggest that the risks of radon at low dose have been overstated. They concluded that there is insufficient evidence to justify the National Radiological Protection Board's proposals for remedial action in homes. ${ }^{46}$ The board says, however, that this review does not reflect the international scientific consensus.

\section{Conclusion}

The radiation story is far from complete. Risk estimates for radiation exposure are founded on shifting ground. If there is an excess risk from environmental radiation it remains undetected by current techniques and is therefore likely to be extremely small. Routine emissions from modern nuclear installations and from weapons testing seem to add little to the overall risks. But the nuclear industry still has a grave responsibility to protect its workers and their children from the effects of radiation and prevent the potentially devastating damage to health from nuclear accidents like the fire at Chernobyl. The effects of radiation on the body are cumulative, and whatever the source it makes sense to limit exposure when possible. Controlling the use of radiation in medicine offers great scope for preventing unnecessary death and illness.

I thank the National Radiological Protection Board and Hazel Inskip for their help with this article.
1 Caufield C. Multiple exposures-chronicles of the radiation age. London: Secker and Warburg, 1989.

National Radiological Protection Board. Living with radiation. 4th ed. Chilton NRPB, 1989.

3 Sumner D. Low level radiation-how dangerous is it? Medicine and War 1990;6:112-9.

4 Beebe GW, Kato H, Land CE. Studies of the mortality of A bomb survivors. 6 . Mortality and radiation dose, 1950-74. Radiation Research 1978;75:136-201.

5 Yoshimoto Y. Cancer risk among children of atomic bomb survivors. FAMA 1990;264:596-600.

6 Sumner D, Wheldon T, Watson W. Radiation risks: an evaluation. 3rd ed. Glasgow: Tarragon Press, 1991

7 Wing S, Shy CM, Wood JL, Wolf S, Cragle DL, Frome EL. Mortality among workers at Oak Ridge National Laboratory. JAMA 1991;265:1397-402.

8 Beral V, Fraser P, Carpenter L, Booth M, Brown A, Rose G. Mortality of employees of the Atomic Weapons Establishment, 1951-82. BMF 1988;297: 757-70.

9 Kendall G, Muirhead CR, MacGibbon BH, O'Hagan JA, Conquest AJ, Goodill AA, et al. Mortality and occupational exposure to radiation: first analysis of the National Registry for Radiation Workers. BMF 1992;304: $220-5$

10 Beral V, Inskip H, Fraser P, Booth M, Coleman D, Rose G. Mortality of employees of the United Kingdom Atomic Energy Authority, 1946-1979. BMF 1985;291:440-7.

11 Shimizu Y, Kato H, Schull WJ, Preston DL, Fujita S, Pierce DA. Life span study report 11. Part 1. Comparison of risk coefficients for site-specific cancer mortality based on the DS86 and T65DR shielded Kerma and Organ doses. Radiation Effects Research Foundation Technical Report Series 1987; No 12:1-56.

12 International Commission on Radiological Protection. Recommendations of the ICRP. Oxford: ICRP, 1990.

13 International Commission on Radiological Protection. Recommendations of the ICRP 1977. Ann ICRP 1978:1.

14 Independent Advisory Group. Investigation of the possible increased incidence of cancer in west Cumbria. London: HMSO, 1984. (Black report.)

15 Committee on Medical Aspects of Radiation in the Environment. Second report. Investigation of the possible increased incidence of leukaemia in young people near the Dounreay nuclear establishment, Caithness, Scotland. London: HMSO, 1988.

16 Committee on Medical Aspects of Radiation in the Environment. Third report. Report on the incidence of childhood cancer in the west Berkshire and north Report on the incidence of childhood cancer in the west Berkshire and north
Hampshire area, in which are situated the Atomic Weapons Research EstablishHampshire area, in which are situated the Atomic Weapons Research Establishment, Aldermas 1989.

17 Forman D, Cook-Mozafarri P, Darby S, Davey G, Stratton I, Doll R, et al. Cancer near nuclear installations. Nature 1987;329:499-505.

18 Cook-Mozaffari PJ, Darby SC, Doll R. Geographical variation in mortality from leukaemia and other cancers in England and Wales, 1959-1980. Office of Population Censuses and Surveys Studies on Medical and Population Subjects. No 51. London: HMSO, 1987.

19 Stapher FK, Clarke RH, Duncan KP. The risk of childhood leukaemia near nuclear establishments. Chilton: National Radiological Protection Board, 1988. (NRPB-R215.)

20 Cook-Mozaffari P, Darby S, Doll R. Cancer near potential sites of nuclear installations. Lancet 1989;ii:1145-7.

21 Kinlen LJ. Evidence for an infective cause of childhood leukaemia: comparison of a Scottish new town with nuclear reprocessing sites in Britain. parison of a Scottish 1988 ;ii: $1323-7$.

22 Kinlen LJ, Clarke K, Hudson C. Evidence from population mixing in British new towns 1946-85 of an infective basis of childhood leukaemia. Lancet 1990;ii:577-82.

23 Kinlen LJ, Hudson C. Childhood leukaemia and poliomyelitis in relation to military encampments in England and Wales in the period of national military service, 1950-63. BMF 1991;303:1357-62.

24 Gardner MJ, Snee MP, Hall AJ, Powell CA, Downes S, Terrell JD. Results of case-control study of leukaemia and lymphoma among young people near Sellafield nuclear plant in west Cumbria. BMF 1990;300:423-34.

25 Nomura T. Parental exposure to $x$ rays and chemicals induces heritable tumours and anomalies in mice. Nature 1982;296:575-7.

26 Ishimaru T, Ishimaru M, Mikami M. Leukaemia incidence among individuals exposed in utero, children of atomic bomb survivors and their controls, Hiroshima and Nagasaki, 1945-79. Hiroshima: Radiation Effects Research Foundation, 1981. (RERF technical report 11-81.)

27 Yoshimoto Y, Neel JV, Schull WJ. Frequency of malignant tumours during the first two decades of life in the offspring (FI) of atomic bomb survivors. Hiroshima: Radiation Effects Research Foundation, 1990. (RERF technical Hiroshima: Radi

28 Urquhart JD, Black RJ, Muirhead MJ, Sharp L, Maxwell M, Eden OB, et al. rquhart JD, Black RJ, Muirhead MJ, Sharp L, Maxwell M, Eden OB, et al.
Case-control study of leukaemia and non-Hodgkins lymphoma in children in Caithness near the Dounreay nuclear installation. BMF 1990;302:687-92. in Caithness near the Dounreay nuclear installation. BMF 1990;302:687-92.
National Radiological Protection Board. Patient dose reduction in diagnostic National Radiological Protection Board. Patie
radiology. Vol 1. No 3. Chilton: NRPB, 1990.

30 Ron E, Modan B. Benign and malignant thyroid neoplasms after childhood irradiation for tinea capitis. F Natl Cancer Inst 1980;65:7-11.

1 Modan B, Ron E, Werner W. Thyroid cancer following scalp irradiation. Therapeutic Radiplogy 1977;123:741-4.

32 Modan B, Baidatz D, Mart H. Radiation induced head and neck tumours. Lancet 1974; ;:277-9.

33 Smith PG, Doll R. Mortality among patients with ankylosing spondylitis after a single treatment course with $x$ rays. BMF 1982;284:449-60.

34 Stewart A, Kneale GW. Radiation dose effects in relation to obstetric $x$ rays and childhood cancers. Lancet 1970; $1: 1185-7$.

35 International Committee on Radiological Protection. The 1983 Washington meeting of ICRP. Radiological Protection Bulletin 1984;57:11.

36 National Radiological Protection Board and Royal College of Radiologists. Patient dose reduction in diagnostic radiology. Report of the Royal College Patient dose reduction in diagnostic radiology. Report of the Royal College
of Radiologists and the National Radiological Protection Board. Documents of Radiologists and the National Radiological Protection
of the National Radiological Protection Board 1990;1(3).

37 Bransby-Zachary MAP, Sutherland GR. Unnecessary $x$ ray examinations. BMF 1989;298:1294.

38 Report of a DHSS working group. Report to the health ministers of England, Wales, Scotland, and Northern Ireland. Breast cancer screening. London HMSO, 1986. (Forrest report)

39 Wall BF, Fisher ES, Shrimpton PC, Rae S. Current levels of gonadal irradiation from a selection of routine diagnostic $x$ ray examinations in Great Britain. London: HMSO, 1980. (NRPB-R105.)

40 National Radiological Protection Board. Board statement on clinical magnetic 
resonance diagnostic procedures. Documents of the National Radiolugical Protection Board, 1991.

41 International Commission on Radiological Protection. Lung cancer risk from indoor exposure to radon daughters. ICRP publication 50. Ann ICRP $1987 ; 17$ (No 1).

42 Committee on the Biological Effects of Ionising Radiation. Health risks of radon and other internally deposited alpha emitters (Beir $I V$ ). Washington, DC: National Radiological Commission, 1988.
43 National Radiological Protection Board. Board statement on radon in homes. Documents of the National Radiological Protection Board 1990;1(1).

4 Department of the Environment. The householder's guide to radon. 2nd ed. London: DoE, 1990.

45 Roscoe RJ, Steenland K, Halperin WE. Lung cancer mortality among nonsmoking uranium miners exposed to radon daughters. fAMA 1989;262: 629-33.

46 Bowie C, Bowie SH. Radon and health. Lancet 1991;337:409-13.

\title{
Quality management in the NHS: the doctor's role-II
}

\author{
D M Berwick, A Enthoven, J P Bunker
}

In last week's issue ( $p$ 235) we argued that the introduction of market conditions into the NHS, designed to achieve greater accountability and create incentives for efficiency and improved quality of care, will not alone be sufficient to achieve improvement. ${ }^{\prime}$ Also needed is a sound and effective method by which medical leaders, managers, and practitioners can implement strategies for improvement. In the absence of such a method efforts to reform the financing of medical care and increases in accountability may result in more waste and fear than progress.

We propose that total quality management (TQM), a collection of approaches to quality, efficiency, and leadership that has matured over the past few decades in industries other than health care, can be used effectively within the health care system as a powerful force for improvement. Last week we reviewed basic principles of TQM and suggested how, with appropriate modifications, these principles can apply to the work of medicine; how market forces can increase the motivation for improvements in quality and efficiency; and how TQM can provide a method for acting on that motivation.

In this article we explore the special opportunities that TQM offers to NHS doctors as leaders of a partnership of managers and other health professionals who together share stewardship of health care in Great Britain. For this partnership of doctors and managers to be effective it will be necessary that doctors understand and participate in management decisions and that managers understand and contribute to the formulation of the goals of medical care.

To achieve fundamental improvement in care new skills will be needed by doctors and managers. These include the ability to work in interdisciplinary teams; to understand medical care as a continually changing and updated process; to collect and interpret data on patient needs, satisfaction, and values, as well as outcome; to accept the need for and take advantage of the opportunities presented by new methods for the drafting, revision, and implementation of standardised patient care management plans or protocols; to collect, aggregate, and analyse and interpret data on the processes of care; and to facilitate the exchange of information with patients. Finally, most important of all is the need for leadership among doctors and managers.

\section{Doctor's essential role in total quality management}

If TQM is to succeed in health care, as we think it can, then doctors will have to have a central role in its practice. This applies even more fundamentally to the NHS than to the disaggregated, fee for service American medical economy. Put boldly, the NHS, unlike much of American health care, is, or at least can be, a system, and because of that it has great potential for rational planned action to meet the needs of those it serves. But that systemic property also creates strong and ineluctable bonds among its components, no one of which can act without the participation of all the others.

The doctors of the NHS, specialists and generalists alike, are key parts of that potential system, and its success may rise or fall depending on the willingness of British doctors to learn, accept, and adapt to the new circumstances of work in an integrated system of care. We believe that TQM offers a set of general principles with which the British medical profession can build an NHS of the future that is proud, capable, supported by its constituents, and, indeed, as satisfying to work in as it has been in the past.

To achieve this transformation will require that doctors accept a body of new skills to learn and practise. Though not taught in medical school, these skills are essential for proper work in an interdependent system of care. Indeed, so crucial are these skills to the successful conduct of medicine in the future that we suggest they be classified as the "new clinical skills" of modern, integrated medical care. They belong in the repertoire of the doctor just as much as the "classical clinical skills" that the new system must preserve and support.

\section{"New clinical skills" of quality management \\ The "new clinical skills" are as follows:}

\section{(1) The ability to perceive and work effectively in} interdependencies

Doctors can and should bear ultimate responsibility for much that occurs in clinical patient care. But it is no longer true, if it ever was, that important patient care processes occur mostly in the transactions between one doctor and one patient. Almost all complex care and much of the care that is simple requires faithful, clear, mutually respectful collaboration among workers with many different credentials. In TQM terms most key processes in health care are cross functional.

For cross functional processes to work in the best interests of those served by them the internal dependencies within those processes must be carefully and explicitly cultivated. On assembly lines workers in TQM organisations learn to ask each other such questions as, "What, exactly do you need from me in order to do your work properly?" and "How have I done at meeting your needs?" These internal "customers and suppliers" seek to clarify their mutual needs and constraints so as to serve each other better.

In a TQM hospital it would be customary for surgeons to approach sisters on the wards regularly with the question, for example, "Is there anything I could have done last week that would have made your work easier?" Teams would exist in which people involved in a common process-such as ordering and reporting laboratory test results, or controlling postoperative pain, or the registration of patients for hospital admission-would take the time to meet, to make their processes or work explicit through such techniques as flow diagrams, and to plan specific steps 